\title{
Combination treatment with triptolide and hydroxycamptothecin synergistically enhances apoptosis in A549 lung adenocarcinoma cells through PP2A-regulated ERK, p38 MAPKs and Akt signaling pathways
}

\author{
GUANMIN MENG $^{1 *}$, WEI WANG ${ }^{1 *}$, KEQUN CHAI $^{1}$, SUWEN YANG $^{2}$, FANGQIONG LI $^{1}$ and KAI JIANG ${ }^{1}$ \\ ${ }^{1}$ Department of Clinical Laboratory, Tongde Hospital of Zhejiang Province, Hangzhou 310012; \\ ${ }^{2}$ Department of Clinical Laboratory, Sir Run Run Shaw Hospital, Medical College, \\ Zhejiang University, Hangzhou 310016, P.R. China
}

Received October 22, 2014; Accepted December 17, 2014

DOI: 10.3892/ijo.2015.2814

\begin{abstract}
Lung cancer is the leading cause of cancer death worldwide. Recently, two plant-derived drugs triptolide (TP) and hydroxycamptothecin (HCPT) both have shown broadspectrum anticancer activities. Our previous study documented that combination treatment with these two drugs acted more effectively than mono-therapy, however, the molecular basis underlying the synergistic cytotoxicity remains poorly understood. In this study, we aimed to clarify the molecular mechanism of TP/HCPT anticancer effect in A549 lung adenocarcinoma cells, by investigating the involvement of phosphatase 2A (PP2A) and PP2A-regulated mitogen-activated protein kinases (MAPKs) and Akt signaling pathways. The results showed that TP and HCPT synergistically exerted cytotoxicity in the growth of A549 cells. Combinatorial TP/HCPT treatment significantly enhanced the activation of caspase-3 and -9, Bax/Bcl-2 ratio, release of cytochrome $c$ from mitochondrial and subsequent apoptosis. While the Akt survival pathway was inhibited, ERK and p38 MAPKs were dramatically activated. Furthermore, the activity of PP2A was significantly augmented. Regulation of p38, ERK and Akt by PP2A was demonstrated, by using a specific PP2A inhibitor okadaic acid (OA). Finally, pharmacological inhibitors OA, SB203580, SP600125 and PD98059 confirm the role of PP2A and its substrates ERK, p38 MAPK and Akt in mediating TP/HCPT-induced apoptosis. Taken together, this study
\end{abstract}

Correspondence to: Professor Wei Wang, Department of Clinical Laboratory, Tongde Hospital of Zhejiang Province, 234 Gucui Road, Hangzhou 310012, P.R. China

E-mail: wangweihz8@163.com

*Contributed equally

Key words: triptolide, hydroxycamptothecin, apoptosis, protein phosphatase $2 \mathrm{~A}$, mitogen-activated protein kinases, Akt provides the first evidence for a synergistic TP/HCPT anticancer activity in A549 cells and also supports a critical role of PP2A and PP2A-regulated signaling pathways, providing new insight into the mode of action of TP/HCPT in cancer therapy.

\section{Introduction}

Lung cancer is one of the most common cancers in the world and accounts for $28 \%$ of all cancer deaths, and non-small cell lung cancer (NSCLC) accounts for $\sim 80 \%$ of lung cancers (1). Currently, surgery, chemotherapy and radiotherapy are still the main conventional treatment of lung cancer. While chemotherapy significantly improves symptoms and the quality of life of patients with lung cancer, however, its efficacy and safety remain a primary concern as toxicity and other side effects of chemotherapy remains a key obstacle (2). Therefore, there is an urgent need for novel strategies or reagents of lung cancer. Alternative medicines, especially herbal therapies $(3,4)$, are becoming more and more attractive. Among these therapies, traditional Chinese medicine (TCM) is probably the best established. Recently, to discover and develop specific herbal extracts and combinations formulas in TCM that can preferentially kill cancer cells without significant toxicity has become an important area in lung cancer therapy.

Triptolide (TP), a diterpenoid triepoxide compound (Fig. 1A), is one of the major biologically active components extracted originally from the Chinese herb Tripterygium wilfordii Hook F (5). Numerous studies have revealed that TP has a myriad of biological properties, including immunosuppression, anti-inflammation, and has been applied to the treatment of autoimmune diseases such as nephritis and rheumatoid arthritis (6). TP has been reported to exert anticancer activity in diverse tumor cell types in vitro, including colon cancer (7), ovarian cancer (8), myeloma (9), myeloid leukemia (10), adrenal cancer (11) and pancreatic cancer cells (12), and to prevent tumor growth in vivo via inhibiting cell proliferation and inducing apoptosis (13). Therefore, with its broad-spectrum anticancer activity, TP has a considerable potential as a chemotherapeutical agent. 
The natural product camptothecin (CPT) is a pentacyclic alkaloid, first isolated in 1966 from the extract of a Chinese plant Camptotheca accuminata. CPT and its analogues have received increasing attention as a promising class of antitumor agents, which act by a unique mechanism inhibiting DNA topoisomerase (14). Among the CPT family, 10-hydroxycamptothecin (HCPT), as shown in Fig. 1B, displays more potent antitumor effects and is less toxic in experimental animals and in human clinical evaluations as compared with CPT. Due to its special cell killing mechanism, that is different from that of other cytotoxic agents, it is difficult to induce cross drug resistance when HCPT is applied together with other anticancer agents. Similarly to TP, HCPT also shows a broad spectrum of antitumor activity against various types of cancers, such as gastric carcinoma, hepatoma, leukemia, bladder carcinoma, and lung cancer (15-18).

A wealth of data now implicate that TP in combination with other anticancer agents, such as idarubicin (19), sorafenib (20), oxaliplatin (7), 5-FU (21), AraC (22), TRAIL (23) and ionizing radiation (24), synergistically increase their cytotoxic effects, suggesting that, next to its potential as a single drug, TP also appears to have potential as a combinatorial drug for the treatment of malignancies. Similarly to the aforementioned findings, our previous study demonstrated that TP combined with HCPT can synergistically suppress the proliferation of pancreatic cancer cell line PANC-1, and induces cell apoptosis (25). However, the detailed mechanism for the synergistic effect of these two herbal medicines remains unclear. The present study was designed to determine the combined efficacy of TP and HCPT on A549 human lung adenocarcinoma cells, and to investigate whether the synergistic cytotoxicity on cell growth may be attributed to induction of apoptosis. Furthermore, to uncover the molecular mechanisms, the involvement of mitochondriadependent biochemical markers, as well as tumor suppressor protein phosphatase $2 \mathrm{~A}$ ( $\mathrm{PP} 2 \mathrm{~A})$, Akt and MAPKs signaling pathways in mediating TP/HCPT-triggered apoptosis were investigated to help us to better use TCMs in cancer therapy.

\section{Materials and methods}

Chemicals. Triptolide ( $\geq 98 \%$ ) was obtained from Beijing Fan-China Biotechnology Co. Ltd. (Beijing, China). 7-ethyl10-hydroxycamptothecin (HCPT) was obtained from Sigma (NY, USA). These drugs were stored in a stock solution in dimethylsulfoxide (DMSO) at $-20^{\circ} \mathrm{C}$ and diluted to various concentrations with serum-free culture medium when used. Okadaic acid (OA) was purchased from Sigma-Aldrich (St. Louis, MO, USA). SB203580, PD98059 and LY294002 were obtained from Calbiochem (San Diego, CA, USA). The 3-(4.5-dimethylthiazol-2-yl)-5-(3-carboxymethoxyphenyl)-2- (4-sulfophenyl)-2H-tetrazolium, inner salt (MTS) was from Promega Co. Ltd. (Southampton, UK), and phenazine methosulfate (PMS) $\left(1 \times 10^{-4} \mathrm{~mol} / \mathrm{l}\right)$ was purchased from Sigma. Annexin V/FITC apoptosis detection kit was obtained from BD Pharmingen (San Diego, CA, USA). Serine/threonine phosphatase assay kit was purchased from Promega (Madison, WI, USA). Mitochondria/cytosol fractionation kit was from Biovision (Mountain View, CA, USA). Antibodies against caspase-3, -9, cytochrome c, Bax ,
Bcl-2, PP2A-A subunit, PP2A-C subunit, Akt and all MAPK family (ERK1/2, p38 and JNK) were all obtained from Cell Signaling Technology (Beverly, MA, USA). Antibodies against caspase-12, GRP78 and CHOP were purchased from Santa Cruz Biotechnology (Santa Cruz, CA, USA). Anti-phosphoPP2A C $\alpha$ (Tyr307) was from Abcam (Cambridge, MD, USA). Antibodies against $\beta$-actin and all of the secondary antibodies were obtained from Kangcheng (Shanghai, China).

Cell culture. Human lung cancer A549 cells (American Type Culture Collection; ATCC CCL185) were maintained in monolayer culture at $37^{\circ} \mathrm{C}$ in a humidified atmosphere with $5 \% \mathrm{CO}_{2}$ in RPMI-1640 medium (Gibco-BRL, USA) supplemented with $10 \%$ fetal bovine serum (FBS) (Sijiqin Biotechnology Co. Ltd., China), $1 \%$ penicillin-streptomycin $(100 \mathrm{U} / \mathrm{ml}$ penicillin and $100 \mu \mathrm{g} / \mathrm{ml}$ streptomycin).

Cytotoxicity assay. To determine the optimal concentration of the combination of TP and HCPT, A549 lung cancer cells ( $1 \times 10^{4}$ cells/well in 96-well plates) were exposed to increasing concentrations of TP $(0,6.25,12.5,25,50,100,200$ and $400 \mathrm{ng} / \mathrm{ml})$ or HCPT $(0,0.25,0.5,1,2,4,8$ and $16 \mu \mathrm{g} / \mathrm{ml})$ for $24 \mathrm{~h}$, respectively. For the cytotoxicity assay of TP/HCPT combination treatment, A549 cells were treated with TP $(25 \mathrm{ng} / \mathrm{ml})$ and variable concentrations of $\operatorname{HCPT}(0,0.5,1,2,4$ and $8 \mu \mathrm{g} / \mathrm{ml}$ ) for $24 \mathrm{~h}$, and cell viability was evaluated by the MTS assay using tetrazolium compound MTS and the electron coupling reagent PMS. After incubation for the indicated time, $20 \mu \mathrm{l}$ MTS/PMS mixture was added to each well; then, the cells were incubated for $1 \mathrm{~h}$ and absorbance was measured at $490 \mathrm{~nm}$. The background absorbance from the control wells was subtracted from the actual absorbance value. Three duplicate studies were performed for each experimental condition. Dose-response curves were plotted on the basis of the data derived from the MTS assay.

Combination index and dose reduction index analyses. The multiple drug effect analysis of Chou and Talalay (26), which is based on a median-effect principle, was used to evaluate the nature of the interaction between TP and HCPT. The combination index $(\mathrm{CI})$ is a parameter that indicates whether the interaction of two or more drugs is synergistic, additive, or antagonistic. Briefly, synergism, additivity and antagonism are indicated by $\mathrm{CI}<1, \mathrm{CI}=1$ and $\mathrm{CI}>1$, respectively. The dose reduction index (DRI) is a parameter that indicates the degree to which a drug dose can be reduced when used in combination with another drug and maintain an equivalent effect level. The CI and DRI for TP/HCPT were calculated based on the data from the MTS assay as described previously $(25,27)$.

Determinations of cell morphology and cell apoptosis. A549 cells $\left(1.5 \times 10^{5}\right.$ cells/well) were seeded in 6-well culture plates for $24 \mathrm{~h}$ and then were treated with TP and HCPT alone or in combination for $24 \mathrm{~h}$, and then photographed under phase-contrast microscope and harvested by centrifugation. For apoptosis determination, we used the Annexin V/ FITC kit as described by the manufacturer. The collected cells were resuspended in binding buffer at a concentration of $1 \times 10^{6}$ cells $/ \mathrm{ml}$. After incubation, $100 \mu \mathrm{l}$ of the solution was 
A

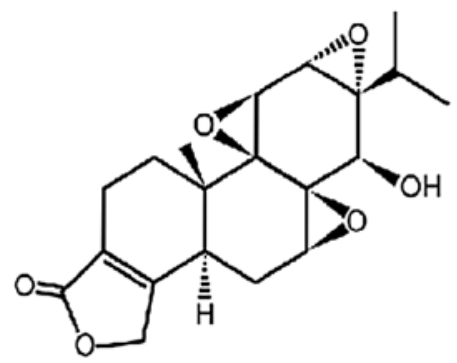

B

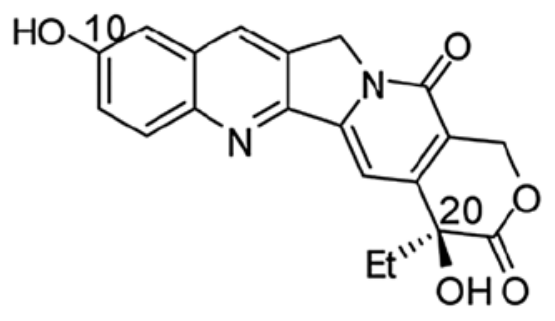

Figure 1. Chemical structures of the compounds. (A) Triptolide (TP). (B) 10-hydroxycamptothecin (HCPT).

added by $5 \mu \mathrm{l}$ of Annexin V-FITC and $5 \mu \mathrm{l}$ of propidium iodide (PI), and then incubated for $15 \mathrm{~min}$ at room temperature in the dark. At the end of incubation, $400 \mu \mathrm{l}$ of binding buffer was added, and the cells were analyzed immediately by flow cytometry. Flow cytometry analysis was performed with untreated cells as a control.

Western blot analysis. Total protein extracts were prepared as described previously (28). Cells were suspended in cell lysis buffer containing $150 \mathrm{mM} \mathrm{NaCl}, 50 \mathrm{mM}$ Tris (pH 7.6), $15 \mathrm{mM}$ EDTA, $1 \mathrm{mM}$ phenylmethylsulfonyl fluoride, $1 \mathrm{mM} \mathrm{Na} \mathrm{VO}_{4}$, and $1 \mathrm{mM} \mathrm{NaF}$, and complete protease inhibitor tablet (Roche, Indianapolis, IN, USA) on ice for $30 \mathrm{~min}$. The lysate solution was then centrifuged at $20,000 \mathrm{~g}$ for $20 \mathrm{~min}$ at $4^{\circ} \mathrm{C}$, and the supernatant protein extract was stored at $-80^{\circ} \mathrm{C}$.

For cytosolic cytochrome $c$ analysis, cytosolic fractions were prepared by using Mitochondria/Cytosol fractionation kit according to the manufacturer's instructions. Briefly, the cells were collected and suspended in cytosolic extraction buffer containing $0.1 \%$ DTT and protease inhibitor on ice for $10 \mathrm{~min}$. The mixture was homogenized in an ice-cold dounce tissue grinder (40-50 strokes) and centrifuged at $700 \mathrm{~g}$ for $10 \mathrm{~min}$. The supernatants were then transferred into fresh tubes, centrifuged at $10,000 \mathrm{~g}$ for $30 \mathrm{~min}$, and the supernatants were collected as cytosolic fraction and stored at $-80^{\circ} \mathrm{C}$.

The concentration of protein in each cell lysate was determined by using a BCA protein assay kit (Pierce, Rockford, IL, USA) with bovine serum albumin (BSA) as the standard. Subsequent western blot analysis was performed as described (reference?) previously. All blots were developed using enhanced chemoluminescence reagents (Super signal dura kit, Pierce) following the manufacturer's instructions.

PP2A phosphatase activity assay. PP2A activity was determined using a serine/threonine phosphatase assay system in accordance with the manufacturer's protocols. Cells were briefly lysed with a phosphatase lysis buffer $(50 \mathrm{mM}$ Tris-HCl pH 7.5, $10 \%$ glycerol, $0.05 \% \beta$-mercaptoethanol, $0.1 \mathrm{mM}$ EDTA, $0.05 \%$ Triton X-100, $0.5 \mathrm{mM}$ PMSF, phosphatase inhibitor cocktail) and measured for phosphatase activity using a PP2A-type specific buffer $(250 \mathrm{mM}$ imidazole $\mathrm{pH} 7.2,1 \mathrm{mM}$ EGTA, $0.1 \% \beta$-mercaptoethanol, $0.5 \mathrm{mg} /$ $\mathrm{ml}$ bovine serum albumin). Free phosphate, generated from a synthetic phosphothreonine peptide RRA(pT)VA specific for PP2A, was quantified by measuring molybdate/malachite green/phosphate complex at $630 \mathrm{~nm}$. EGTA and EDTA were included in the lysis buffer to inhibit PP2B and PP2C, respectively. The effective range of the assay is 100-4,000 pmol of phosphate.

Statistics. Results are expressed as mean \pm SE. Statistical significance between groups was determined using one-way ANOVA and Dunnett's comparison. $\mathrm{p}<0.05$ were considered statistically significant.

\section{Results}

Combination treatment of TP and HCPT induced growth inhibition of A549 cells. The effect of TP or HCPT as a single agent on the growth of the A549 lung adenocarcinoma cells was first assessed. As shown in Fig. 2A, either TP or HCPT individually caused a markedly dose-dependent reduction in cell viability, with $50 \%$ growth inhibition $\left(\mathrm{IC}_{50}\right)$ of $273.2 \mathrm{ng} / \mathrm{ml}$ and $8.62 \mu \mathrm{g} / \mathrm{ml}$, respectively. Next, we adopted a combination treatment by keeping the concentration of TP constant at $\mathrm{IC}_{10}$ value $(25 \mathrm{ng} / \mathrm{ml})$, together with varying concentrations of HCPT $(0-8 \mu \mathrm{g} / \mathrm{ml})$. We found that the combined treatment of TP and HCPT (TP/HCPT) substantially suppressed A549 cell growth as compared to single drug alone. Fig. 2B showed a 3.7-fold decrease of $\mathrm{IC}_{50}$ for HCPT when added in presence of $25 \mathrm{ng} / \mathrm{ml} \mathrm{TP}\left(\mathrm{IC}_{50}=2.34 \mu \mathrm{g} / \mathrm{ml}\right)$, compared to HCPT treatment alone, indicating that the combination treatment with TP and HCPT is more effective in inhibition of A549 cell growth than single drug treatment.

In order to assess their synergistic effect on A549 cells, we evaluated synergy using CalcuSyn software to evaluate the combination index (CI) which was originally described by Chou and Talalay $(26,27)$, when synergism, additivity and antagonism are defined by $\mathrm{CI}<1, \mathrm{CI}=1$ and $\mathrm{CI}>1$, respectively. The CI value was nearly 1.20 when A549 cells were exposed to the combination of $25 \mathrm{ng} / \mathrm{ml} \mathrm{TP}$ and $0.5 \mu \mathrm{g} / \mathrm{ml} \mathrm{HCPT}$, indicating a slight antagonism. However, when A549 cells were exposed to the combination of $25 \mathrm{ng} / \mathrm{ml} \mathrm{TP}$ and variable concentrations of HCPT $(1-8 \mu \mathrm{g} / \mathrm{ml})$, it demonstrated clear evidence of synergy since the CI value ranged from 0.4 to $0.7(<1)$ (Table I). Similar to our recent findings in pancreatic cancer cell line PANC-1 (25), a higher synergistic effect (lower CI value) was observed for lower dose combination. Once the 
A

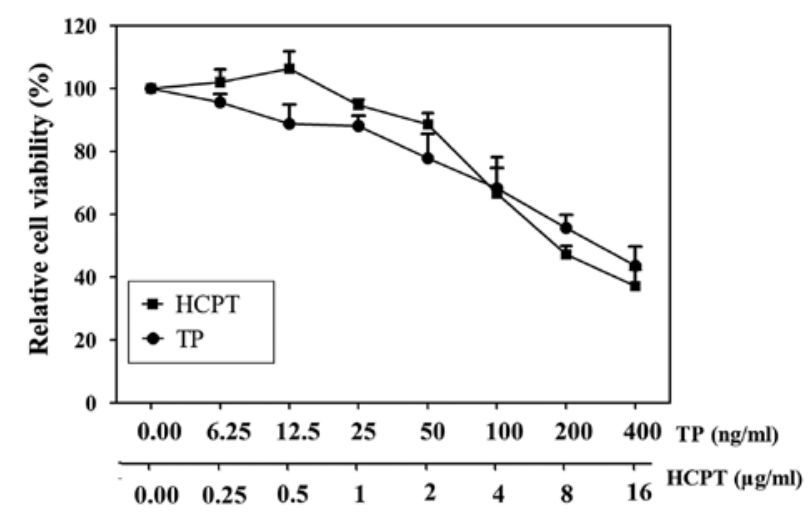

B

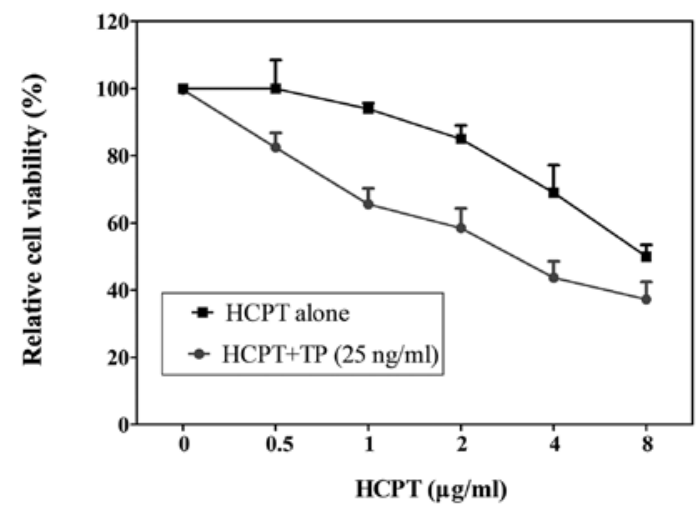

Figure 2. Combinatorial effects of TP and HCPT on A549 cells. (A) Individual effect of TP or HCPT on cellular growth. A549 cells were treated with graded concentrations of TP $(6.25,12.5,25,50,100,200$ and $400 \mathrm{ng} / \mathrm{ml}$, respectively) or HCPT $(0.25,0.5,1,2,4,8$ and $16 \mu \mathrm{g} / \mathrm{ml}$, respectively) for $24 \mathrm{~h}$. Cellular growth was measured by MTS assay. Data are expressed as the means \pm standard error (SE) $(n=4)$. (B) The combined effects of TP and HCPT on cellular growth. A549 cells were treated with HCPT $(0-8 \mu \mathrm{g} / \mathrm{ml})$ combined with or without TP $(25 \mathrm{ng} / \mathrm{ml})$ for $24 \mathrm{~h}$, and the cell proliferation was monitored. Data are expressed as the means \pm SE $(n=4)$.

Table I. Combination index $(\mathrm{CI})$ and dose reduction index (DRI) analysis for triptolide and hydroxycamptothecin combination therapy in A549 cells.

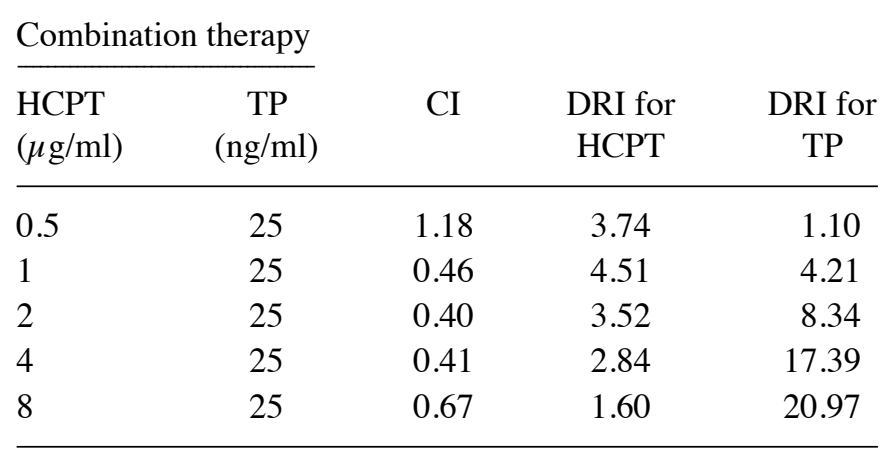

The affected fraction of cell survival after drug treatment is calculated with respect to control, and CalcuSyn software was run with relevant data as per in Materials and methods, and the CI and DRI values of the different combinations is computed. CI determine the type of interaction [additive $(\mathrm{CI}=1)$; synergistic $(\mathrm{CI}<1)$; antagonistic $(\mathrm{CI}>1)]$. The DRI determines the magnitude of dose reduction allowed for each drug when given in synergistic combination, as compared with the concentration of a single agent that is needed to achieve the same effect. interaction between the two agents was found to be synergistic, we next sought to determine the dose reduction index (DRI) values for TP and HCPT in A549 cancer cells. The DRI analysis further indicated that TP/HCPT combination has the potential to reduce both the doses of TP (ranging from 1.10- to 20.97-fold dose reduction) and HCPT (ranging from 1.60- to 3.74-fold dose reduction) in A549 cells (Table I). In all the subsequent experiments, we treated the cells with the combination of TP $(25 \mathrm{ng} / \mathrm{ml})$ and HCPT $(1-4 \mu \mathrm{g} / \mathrm{ml})$ and TP/ HCPT exhibited higher synergistic effect in inhibiting the growth of A549 lung adenocarcinoma cells.

Treatment with TP and HCPT synergistically induced apoptosis of A549 cells. To investigate the effect of TP/HCPT on apoptosis in A549 cells, Annexin V/propidium iodide (PI) staining-based FACS analysis was performed to detect the externalization of phosphatidylserine on the cell membrane, a hallmark of early apoptosis. Cells undergoing early-stage apoptosis are stained with Annexin V-FITC-positive and PI-negative. Fig. 3A quantifies the increase in apoptotic cells labeling with Annexin $\mathrm{V}^{+} / \mathrm{PI}^{-}$, which increases from $0.4 \%$ in the control group to 6.2 and $7.2 \%$ in the TP- and HCPT-treated group, respectively. Various combinatorial treatments resulted in more apoptotic cells than either single-drug treatment alone, by increasing the apoptosis rate up to $12,17.8$ and $26.7 \%$. It revealed that various combination treatments induced significantly higher percentage of apoptosis as compared to either TP or HCPT treatment alone (Fig. 3B), indicating TP/HCPT can promote apoptosis.

Synergistic effect of TP and HCPT on cell apoptotic pathways. In order to determine whether TP/HCPT induced apoptosis is mediated via the mitochondria-dependent and/or the ER stress-triggered signaling pathways, we examined the effects of TP/HCPT on the related protein level changes by western blot assay. Initially, the expression of caspase-9, -3 , cytochrome $c$ (cytosolic), Bax and Bcl-2 were examined to evaluate the mitochondrial apoptotic pathways. Caspase-9 is known to be involved in the activation of the caspase cascades for cleaving and activating caspase-3, which is an integral step in most apoptotic events. The results indicated that TP or HCPT each only resulted in a slight upegulation of active (cleaved) caspase-3 and -9 production, whereas the combinatorial TP/HCPT treatment caused pronounced upegulation of active caspase-3 and -9 (Fig. 4A), suggesting that enhanced cell apoptosis is mediated through activation of caspase-3 and -9 pathway. In addition, the combined treatment also augmented the release of cytochrome $c$ from mitochondria, diminution of Bcl-2, and marked increase in Bax expression (Fig. 4A), which displayed features of mitochondria-dependent apoptotic signals.

Next, we further determined the expression of three hallmarks of endoplasmic reticulum stress (ERS), including glucose regulated protein 78 (GRP78) and CHOP which are known to promote ER stress-induced apoptosis $(29,30)$, as well as ER-specific caspase-12 (31). It revealed that TP/HCPT combination treatment upegulated the GRP78 expression, which is a key regulator in ER stress signaling that has a dynamic capacity to regulate the balance between cell survival and apoptosis (Fig. 4B). However, CHOP and caspase-12, 
A
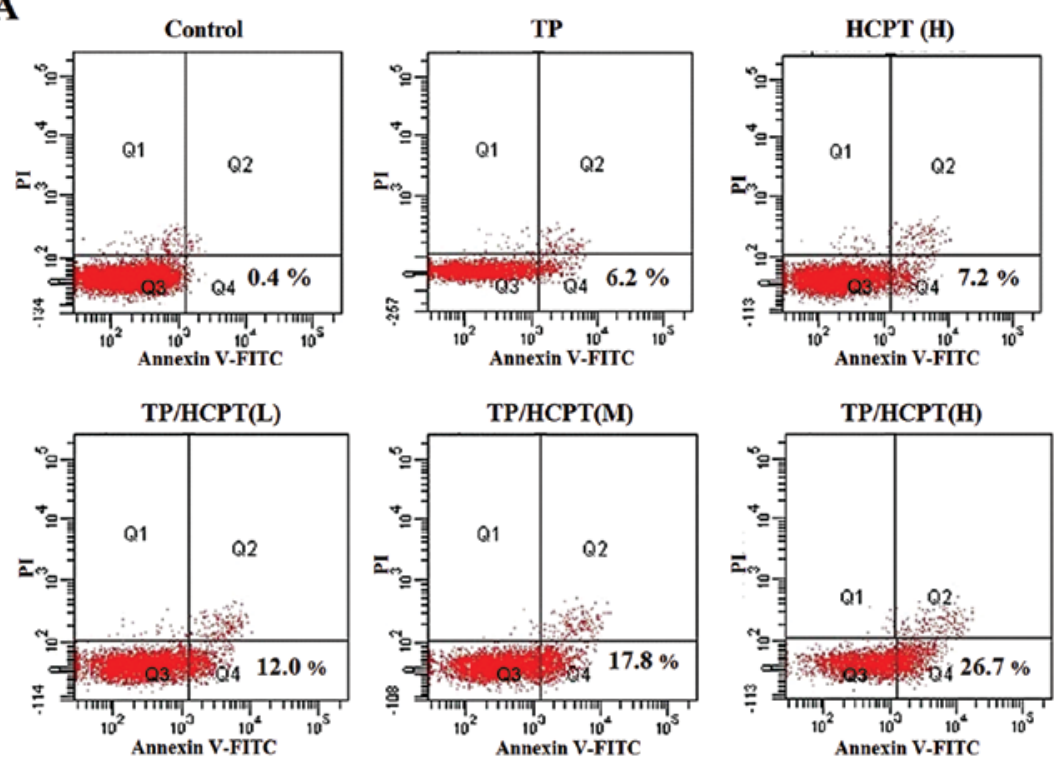

B

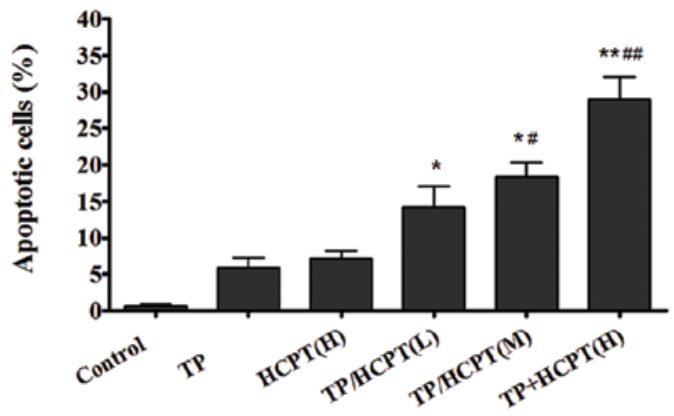

Figure 3. Effect of TP and HCPT combination treatment on the induction of apoptosis. (A) Flow cytometry analyses of A549 cells under various treatments using double staining with Annexin V (horizontal line) and propidium iodide (PI, vertical line); TP, $25 \mathrm{ng} / \mathrm{ml}$ TP; HCPT(H), $4 \mu \mathrm{g} / \mathrm{ml} \mathrm{HCPT}$; TP/HCPT(L), $25 \mathrm{ng} / \mathrm{ml} \mathrm{TP}+1 \mu \mathrm{g} / \mathrm{ml} \mathrm{HCPT}$; TP/HCPT(M), $25 \mathrm{ng} / \mathrm{ml} \mathrm{TP}+2 \mu \mathrm{g} / \mathrm{ml} \mathrm{HCPT}$; TP/HCPT(H), $25 \mathrm{ng} / \mathrm{ml} \mathrm{TP}+4 \mu \mathrm{g} / \mathrm{ml} \mathrm{HCPT}$. (B) Bar graphs representing the proportion of early stage apoptosis cells (Annexin V-positive/PI-negative). Data are expressed as the means $\pm \mathrm{SE}$ ( $\mathrm{n}=3$ ). ${ }^{*} \mathrm{p}<0.05$ and ${ }^{* *} \mathrm{p}<0.01 \mathrm{vs}$. TP group; ${ }^{\#} \mathrm{p}<0.05$ and ${ }^{\# \#} \mathrm{p}<0.01$ vs. HCPT group.

the critical executioners involved in the ER stress-mediated apoptosis, were not affected by the treatments. These results suggest that the apoptotic action of TP/HCPT is mainly mediated by caspase- 9 and -3 mitochondrial apoptotic pathways.

Synergistic effect of TP and HCPT on PP2A activity as well as MAPKs and Akt signaling pathways. Multiple signaling pathways, such as mitogen-activated protein kinases (MAPKs) family and protein kinase B (Akt) signal transduction pathways, are essential for cell survival and important for the regulation of apoptosis (32-34). To begin elucidating the signaling events that mediate TP/HCPTinduced apoptosis, we first analyzed the activation of three MAPK effectors (p38, JNK and ERK1/2) and Akt in A549 cells using phospho-specific antibodies. As shown in Fig. 5A, TP/HCPT treatment synergistically evoked a dramatic phosphorylation of ERK1/2 and p38 (i.e., activation), in a similar pattern that a maximum response occurred when TP was combined with HCPT at the highest concentration $(4 \mu \mathrm{g} / \mathrm{ml})$. However, no significant effect of TP/HCPT combination on JNK phosphorylation was observed. The levels of nonphosphorylated p38, JNK and ERK were unaffected by either mono-therapy or combinatorial treatment. On the other hand, we observed that while the phosphorylated Akt was slightly stimulated by TP alone, however, combination treatment of TP and HCPT significantly inhibited TP-induced activation of Akt (Fig. 5A). In particular, cells exposed to TP combined with the highest concentration of HCPT underwent remarkable decrease in Akt phosphorylation.

Protein phosphatase 2A ( $\mathrm{PP} 2 \mathrm{~A})$ is one of the major protein serine/threonine phosphatases that regulate diverse cellular functions such as cell division and transcription (35), and has attracted considerable attention due to its apoptosis-inducing effect and tumor-suppressing function (36-38). Hence, we evaluated the contribution of PP2A by accessing the phosphatase activity, and the levels and modification of PP2A composition subunits. We noted that the activity of PP2A was stimulated by both TP and HCPT mono-therapies. Moreover, combinatorial TP/HCPT treatment markedly enhanced the activity of PP2A in a dose-dependent manner, with the maximum response 
A

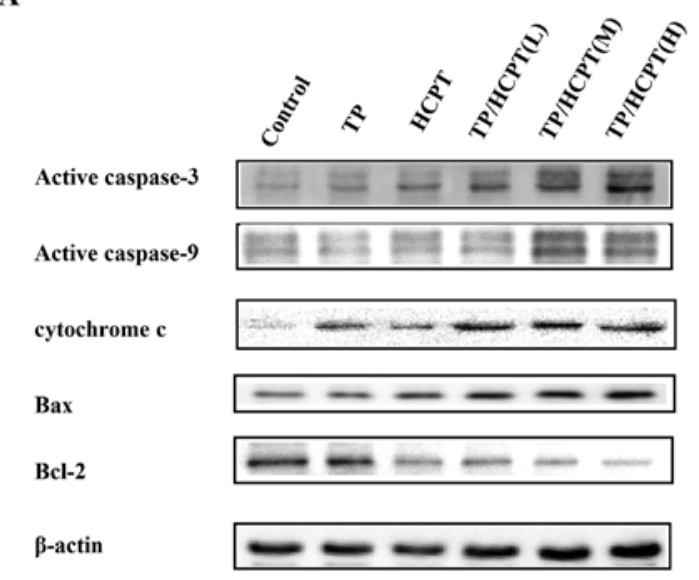

B

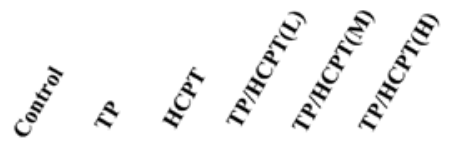

GRP78

caspase-12

CHOP

$\beta$-actin

Figure 4. Effect of TP/HCPT treatment on the apoptosis-associated proteins in A549 cells. A549 cells under various treatments were harvested for examining the associated protein levels. (A) Mitochondrial apoptotic pathway detected by antibodies against caspase-3, -9, cytochrome $c$, Bax and Bcl-2. (B) ER stress apoptotic pathway detected by antibodies against caspase-12, GRP78 and CHOP. $\beta$-actin was used as an internal control. occurring when TP was combined with the highest concentration of HCPT (Fig. 5B). Furthermore, alteration of PP2A composition subunit levels was observed. As shown in Fig. 5C, structural A subunit was dramatically enhanced by TP/HCPT combination treatment. In contrast, TP/HCPT caused a marked decrease in the level of total PP2A-C. Subsequently, the phosphorylation at Tyr307 (Y307) of the PP2A-C subunit was investigated because it contributes to decrease in PP2A activity (39). It was noteworthy that TP/HCPT treatment induced the downregulation of PP2Ac (Y307) phosphorylation, which was in accordance with PP2A activation.

TP/HCPT induced apoptosis is mediated through PP2Aregulated ERK, p38 MAPK and Akt signaling pathways. PP2A has been demonstrated to act as a deactivator of several kinases as its substrates, such as MAPKs and Akt (40-42). To confirm this role, we used okadaic acid (OA), a selective inhibitor of PP2A, and to examine whether inhibition of PP2A by OA modulates the phosphorylation status of ERK1/2, p38 MAPKs and Akt in TP/HCPT-treated A549 cells. Notably, pretreatment of A549 cells with $50 \mathrm{nM}$ of OA effectively abolished both the basal level as well as the TP/HCPT-induced increase in PP2A activity (Fig. 6A). After verifying the inhibition of PP2A activity by OA, we investigated the role of PP2A in the dephosphorylation of ERK1/2, p38 and Akt signaling cascades. As shown in Fig. 6B, OA on its own had no effect on the activation of either ERK1/2 MAPK or p38 MAPK. However, inhibition of PP2A by OA enhanced the ability of TP/HCPT to increase the phosphorylation of ERK1/2 and p38, indicating that the dephosphorylation of the ERK and p38 MAPK signaling pathways might be PP2A-dependent.
A

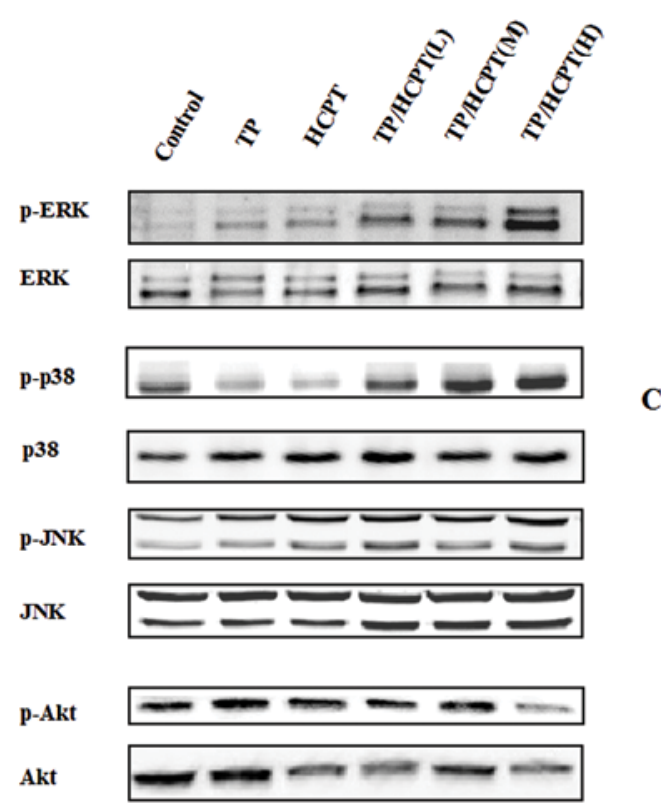

B

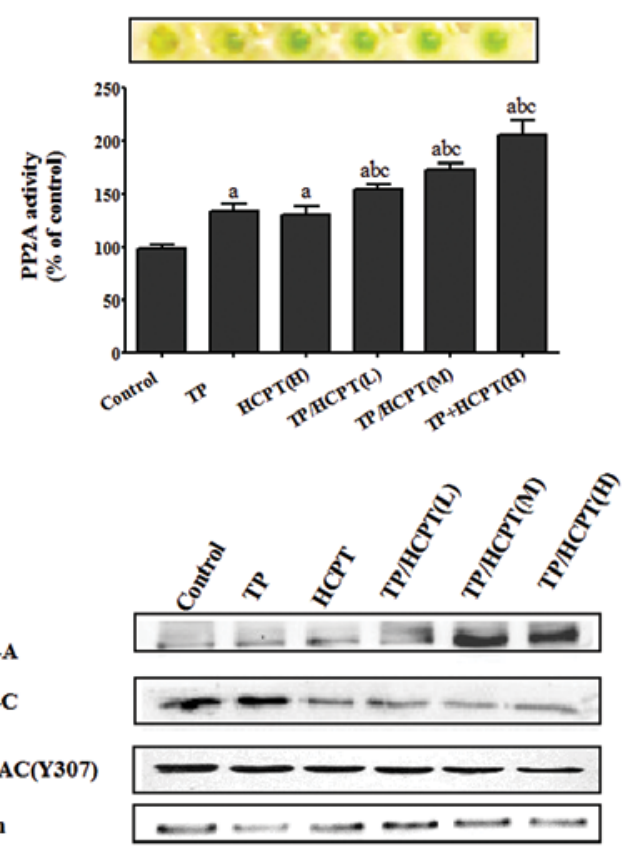

Figure 5. Effect of TP/HCPT treatment on the MAPKs and Akt signaling pathways as well as PP2A activity in A549 cells. (A) The cell lysates from A549 cells under various treatments were subjected to immunoblot analysis with antibodies that detect either the specified protein or the specified protein when it is phosphorylated at a designated site, which are representative of at least 3 separate experiments. (B) Phosphatase activity of PP2A was determined with phosphatase assay system (see Materials and methods). The values are expressed as a percentage of the control (untreated cells; $100 \%$ PP2A activity). a, ${ }^{*} \mathrm{p}<0.05$ vs. the control group; $b,{ }^{\prime} p<0.05$ vs. TP group; $c$, " $p<0.05$ vs. HCPT group $(n=4)$. (C) Alterations of various PP2A subunit levels detected by antibodies against the PP2A-A subunit, PP2A-C subunit and phospho-PP2A C $\alpha$ (Tyr307). $\beta$-actin was used as an internal control. 
A

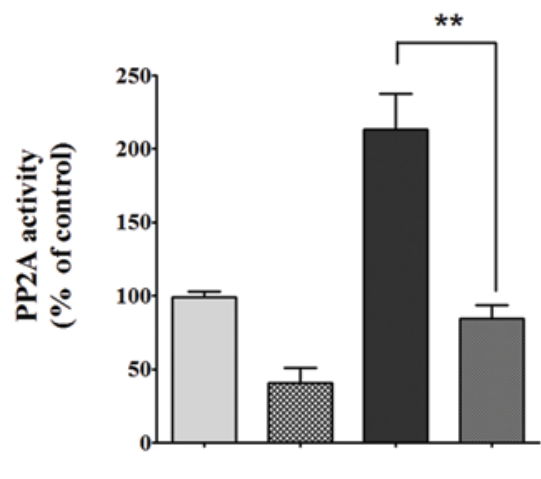

TP/HCPT $\quad-\quad-\quad+\quad+$

OA

C

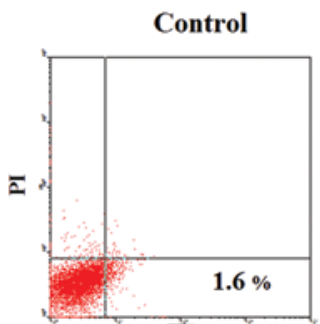

Annexin V-FITC

PD98059

+ TP/HCPT

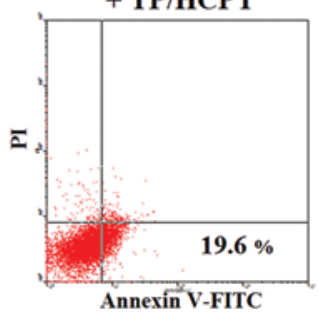

B
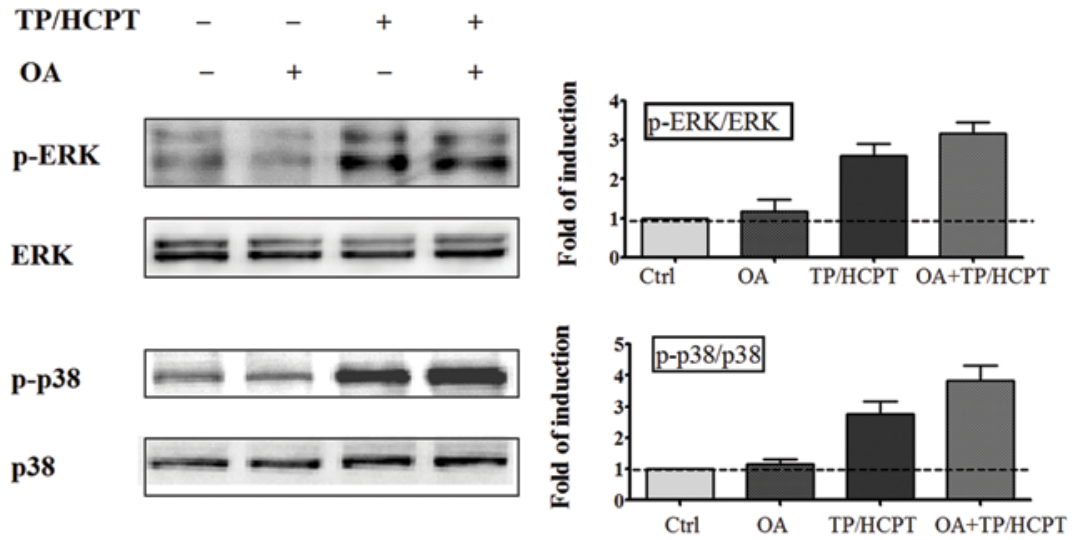

p-Akt

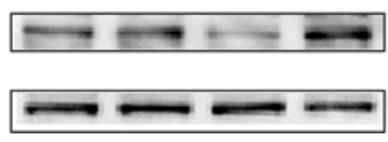

Akt

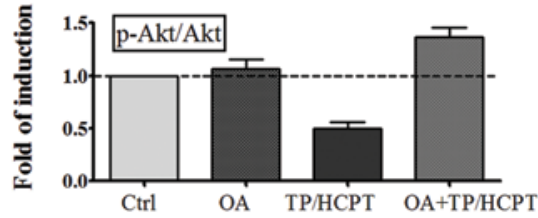

Figure 6. Effect of PP2A inhibition on ERK, p38 and Akt signaling pathways, as well as TP/HCPT-induced apoptosis. (A) TP/HCPT-enhanced PP2A activity was inhibited by OA. A549 cells were also treated with OA $(50 \mathrm{nM})$ for $2 \mathrm{~h}$ prior to $24 \mathrm{~h}$ of combinatorial treatment with TP $(25 \mathrm{ng} / \mathrm{ml}) \mathrm{and} \mathrm{HCPT}(4 \mu \mathrm{g} / \mathrm{ml})$. Cell lysates were prepared and assayed for phosphatase activity of PP2A. The values are expressed as a percentage of the control (untreated cells; $100 \%$ PP2A activity). ${ }^{* *} \mathrm{p}<0.01$ vs. the TP/HCPT group (n=3). (B) Effect of PP2A inhibition on ERK, p38 and Akt signaling pathways. Cell lysates after different treatments were prepared and subjected to western blot analysis. The results are representative of three independent experiments, and the corresponding densitometric analyses for relative protein expression were shown in the right hand panels. (C) Effect of inhibitors of pp2A, p38, ERK and Akt on TP/HCPT-induced apoptosis. The cells were treated with OA $(50 \mathrm{nM})$, p38 inhibitor-SB $203580(10 \mu \mathrm{M})$, ERK inhibitor-PD $98059(10 \mu \mathrm{M})$ and Akt inhibitor-LY294002 $(25 \mu \mathrm{M})$ for $2 \mathrm{~h}$ prior to $24 \mathrm{~h}$ of TP/HCPT treatment. Then the cells were collected and analyzed using Annexin V/PI double staining, and bar graphs shown in the right hand panel representing the apoptotic rates. ${ }^{*} \mathrm{p}<0.05$ and ${ }^{* *} \mathrm{p}<0.01$ vs. the TP/HCPT group $(\mathrm{n}=3)$.

Despite differential involvement of MAPKs and Akt survival signaling cascades upon treatment with TP and HCPT, OA also effectively prevented Akt dephosphorylation induced by TP/HCPT (Fig. 6B), indicating all the ERK1/2 MAPK, p38 MAPK and Akt signaling cascades might be downstream of PP2A.

Next, to further identify the role of PP2A and its substrates in mediating TP/HCPT-induced apoptosis, we used specific pharmacological inhibitors of the different pathways to evaluate the apoptotic rates. As shown in Fig. 6C, OA pretreatment greatly abrogated the apoptotic effect of TP/HCPT, implying a role for PP2A in TP/HCPT-stimulated apoptosis. PD98059, an inhibitor of MEK1, which is the kinase responsible for the activation of ERK1/2 MAPK, significantly reduced the synergistic effect of TP and HCPT on apoptosis. Similarly, pretreatment of cells with SB203580, a well-established inhibitor of p38 MAPK, also inhibited the apoptotic effect of TP/HCPT, suggesting the activation of ERK and p38 are required for apoptosis caused by TP/HCPT. We then employed LY294002, a well-known PI3K inhibitor, to examine whether the PI3K/Akt 


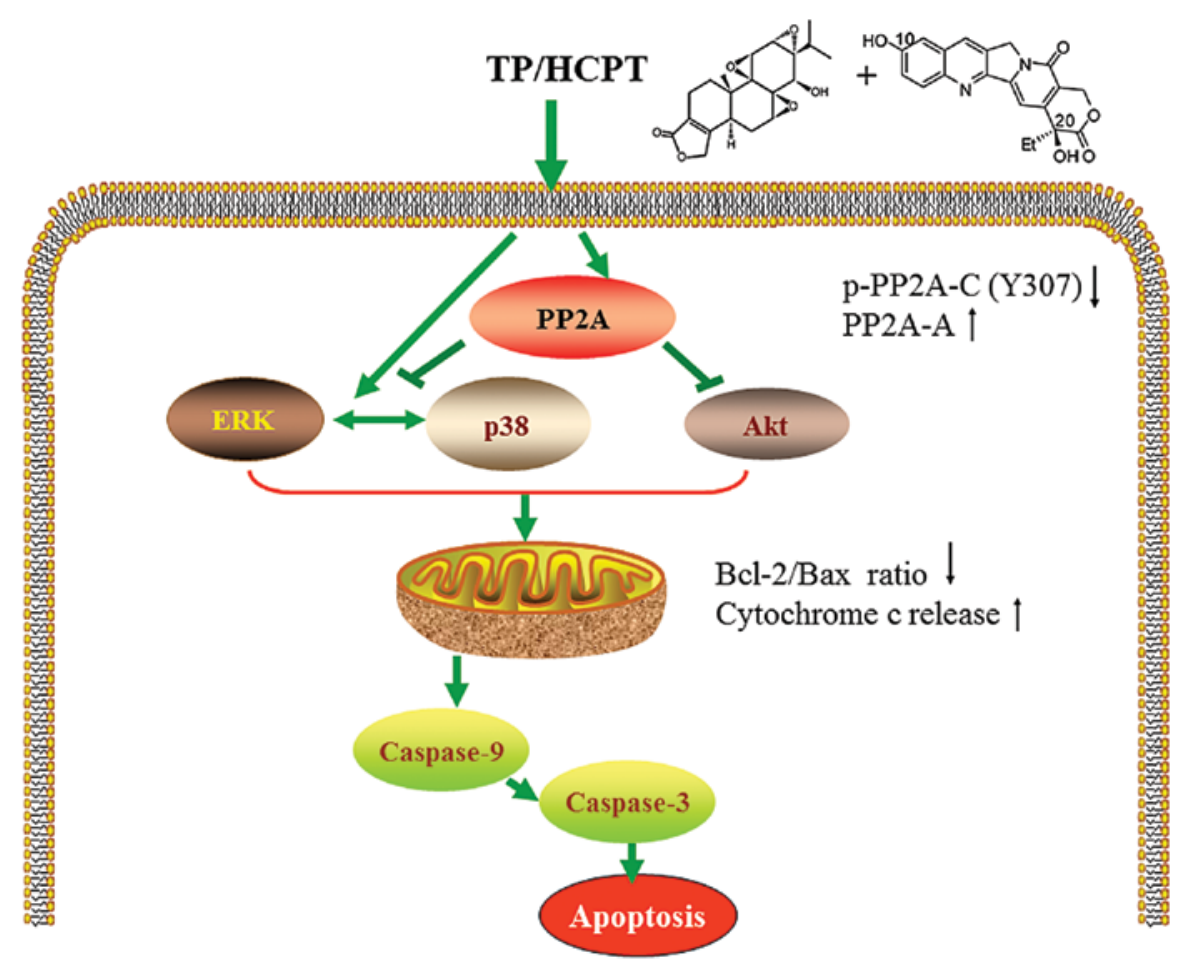

Figure 7. Schematic diagram of the mechanism by which TP together with HCPT induce apoptosis in A549 lung adenocarcinoma cells. TP and HCPT synergistically stimulate the activation of tumor suppressor PP2A, and modulate PP2A-regulated intracellular signaling pathways, involving activation of ERK1/2 and p38 MAPKs cascades, and inhibition of Akt survival pathway. Finally, combinatorial TP/HCPT drug regimens cause Bax- and Bcl-2-mediated mitochondrial apoptotic pathways, resulting in caspase-9 and -3 triggered cell apoptosis.

signaling pathway also plays a key role in mediating apoptosis. Our data showed that, contrary to the effect observed with the ERK and p38 inhibitors, LY294002 dramatically potentiated TP/HCPT-stimulated apoptosis by $40 \%$, indicating that inhibition of the PI3K/Akt signaling pathway was critical to the combinational effect of TP and HCPT on apoptosis. Together these results indicate that TP/HCPT trigger apoptosis plausibly by activation of the p38 and ERK MAPK cascades, and inhibition of the Akt survival pathway through a mechanism involving activation of PP2A.

\section{Discussion}

Recently, the interest in exploiting traditional Chinese medicine (TCM) for prevention or treatment of cancer has been greatly increased (4). Among TCMs, two well-known herbal medicines triptolide (TP) and hydroxycamptothecin (HCPT), that are produced mainly in regions of China (as well as some other Asian areas such as Japan and North Korea), have been found to exhibit anticancer potential both in vitro and in vivo $(16,43,44)$. Our previous study, which determined the effects of TP and HCPT on pancreatic cancer, demonstrated thatTP combined with HCPT synergistically increase their cytotoxic effect in pancreatic cancer cells PANC-1, suggesting that the combination of TP and HCPT may possess clinical potential for the treatment of cancers (25). As yet, however, the molecular basis underlying the synergistic cytotoxicity of these two herbal medicines has remained poorly understood. We attempted to investigate the efficacy of combinatorial TP/HCPT treatment in human non-small cell lung cancer
(NSCLC) cell line A549 in vitro. In the present study, the results present an extension of our prior findings by showing that the synergistic TP/HCTP anticancer effect in A549 lung adenocarcinoma cells is mediated by apoptosis induction via activation of mitochondria-dependent apoptotic pathway, along with enhanced PP2A activity as well as activation of ERK1/2 and p38 MAPKs cascades and inhibition of Akt survival pathway, which provide new insight into the mode of action of the traditional Chinese medicine TP together with HCPT in cancer therapy.

A wealth of data indicate that TP, with its broad-spectrum anticancer activity, can be used as a single agent to treat different tumors. Recently, several pieces of evidence have been reported indicating the possibility of using TP in combination with other anticancer drugs to improve efficacy; also as a single drug, TP has been found to enhance the action of other anticancer agents or therapies, such as idarubicin (19), sorafenib (20), 5-FU (21) and ionizing radiation (24), making the combination superior to mono-therapy alone. In addition to the aforementioned agents, our previous study also demonstrated TP combined with HCPT have therapeutic potential for pancreatic cancer (25). Thus, elucidating the mode of action of TP together with HCPT in killing cancer cells will help us to understand and to better use TCMs in cancer therapy. Our present study by keeping $\mathrm{TP}$ concentration at its $\mathrm{IC}_{10}$ value combined with variable concentrations of HCPT demonstrated a significant decrease in $\mathrm{IC}_{50}$ of $\mathrm{HCPT}$ which indicated the increased cytotoxicity of HCPT by TP, suggesting that the combinatorial TP/HCPT drug regimens substantially suppressed A549 cell growth as compared to either mono- 
therapy. Further CI analyses revealed a synergistic interaction between the two agents in most of the combination doses tested. Similar to our recent findings in pancreatic cancer cell line PANC-1 (25), a higher synergistic effect (lower CI value) was observed for lower dose combination. Moreover, combinatorial TP/HCPT treatment yielded favorable DRI values which allowed for both TP and HCPT dose reduction. Taken together, such synergistic interactions between TP and HCPT provide an opportunity to reduce the doses of the individual drug and thereby reducing their adverse toxicities.

Apoptosis (programmed cell death), is characterized by several morphological and biochemical events (45). To determine whether the decrease in A549 cells growth is attributed to apoptosis seems vital, as the induction of apoptosis in cancer cells is the major indicator of anticancer effects. Hereby, Annexin V/PI staining-based FACS analysis was employed to evaluate the proportion of apoptotic cells. Apoptotic cells are characterized by a series of morphological alterations such as shrinkage of the cells and the nuclei, loss of adhesion to adjacent cells, membrane blebbing, DNA fragmentation and chromatin condensation (46). In the present study, A549 cells treated with combinatorial TP/HCPT treatment exhibited evidence of apoptotic morphology, i.e., cellular shrinkage, cytoplasmic blebbing and condensation of nuclei, which are characteristics of apoptosis (data not shown). These observations were confirmed by flow cytometry analysis which clearly revealed the number of apoptotic cells dramatically increased after combined exposure, suggesting that TP acts synergistically with HCPT in promoting apoptosis which greatly contributed to the inhibition of NSCLC A549 cell growth.

Three major distinct pathways have been reported to mediate TP-induced apoptosis in various cell lines, including the death receptor-mediated (extrinsic), mitochondrial-mediated (intrinsic) and the endoplasmic reticulum (ER) stress pathway $(11,12,23,47)$. Mitochondria are known to play a crucial role in the apoptotic cell death induced by anticancer agents (48-50). In the present study, we did observe that the combined treatment of TP and HCPT induced activation of caspase-3, -9 and release of cytochrome $c$ from mitochondria into the cytosol, which are regarded as hallmarks of the mitochondria-mediated apoptotic pathway. Moreover, we found that combinatorial $\mathrm{TP} / \mathrm{HCPT}$ drug regimens resulted in a dramatic increase in expression of pro-apoptotic protein Bax, while the expression of anti-apoptotic protein Bcl-2 was markedly inhibited, suggesting a shift in the dynamic balance between the outputs of pro-apoptotic and anti-apoptotic pathways. Based upon the fact that the $\mathrm{Bcl}-2 / \mathrm{Bax}$ ratio plays a crucial role in cancer cell apoptosis (51), we reasoned that the reduction in $\mathrm{Bcl}-2 / \mathrm{Bax}$ ratio by $\mathrm{TP} / \mathrm{HCPT}$ would allow less Bcl-2-Bax complex. The net effect would be the release of more free Bax, which then translocated into the mitochondrial membrane and induced the opening of the mitochondrial permeability transition pore to allow the release of cytochrome $c$ and ultimately triggered the caspase cascade activation. There is emerging evidence for a close ER-mitochondria relationship (52), and cross-talk between mitochondrial and ER plays an essential role in determining cell commitment to apoptosis $(53,54)$. Therefore, we further investigated the hallmarks of ER stress-mediated apoptosis, including glucose-regulated protein 78 (GRP78) and its downstream pro-apoptotic proteins $\mathrm{CHOP}$ and caspase- 12 .
GRP78 has been documented as a key regulator in ER stress signaling that has a dynamic capacity to regulate the balance between cell survival and apoptosis in ER-stressed cells (29). TP mono-therapy has been reported to downregulate GRP78 and leads to ER stress-mediated apoptosis in pancreatic cancer cells (12). Intriguingly, in stark contrast, our study presented herein revealed that $\mathrm{TP} / \mathrm{HCPT}$ combination treatment upegulated the expression of GRP78, while the downstream proteins CHOP and caspase-12, as the critical executioners involved in ER stress-mediated apoptosis $(30,31)$, were not affected. It is possible that in the early stage of ER stress, the GRP78 was activated by TP/HCPT to alleviate the stress, thereby restoring the ER homeostasis and leading to prevention of the induction of downstream CHOP and caspase-12. Taken together, these findings suggest that combinatorial TP/HCPT drug regimens induce caspase-dependent apoptosis in A549 lung cancer cells mainly through modulating the Bax- and Bcl-2-triggered mitochondrial pathway.

Many studies have been reported that the pro-apoptotic activity of TP is due to its modulation of apoptosis-activating proteins $(10,47,55)$. It appears from these studies that TP influences multiple proteins and pathways associated with cell growth and survival. Likewise, many studies demonstrate that HCPT can induce apoptosis of various cancer cells by influencing the expression of cancer suppression genes. The direct targets of TP together with HCPT, however, remain unidentified. Numerous studies have reported that MAPKs and Akt/ PKB signal transduction pathways play crucial roles in a variety of chemotherapeutic agent-induced apoptotic signaling $(33,34)$. The three distinct sets of MAPKs are known to be activated differentially depending on the cell type and the nature of the stimuli administered $(56,57)$. Our study demonstrated that the combined treatment of TP and HCPT exhibited an enhancing effect on both the phosphorylation of ERK and p38. Of the MAPKs, ERK1/2 behaves as a mitogen-activated factor that is believed to mediate both cell proliferation and survival, whereas p38 and JNK are activated in response to cellular stresses and appear to exert both protective as well as pro-apoptotic effects (57-59). Intriguingly, in the present study, pretreatment of the cells with either ERK-inhibitor PD 98059 or p38-inhibitor SB 203580 could effectively abolished the apoptotic effect of TP/HCPT, indicating that the activation of mitogenic stimuli-activated ERK and stress-induced p38-MAPK both contribute to TP/HCPT-induced apoptosis. Next, we tried to characterize the phosphorylation status of Akt which is known as an anti-apoptotic kinase (34). In the present study, we found that TP/HCPT triggered remarkable downregulation of Akt pathway. Moreover, contrary to the effect observed with the ERK and p38 inhibitors, inhibition of the Akt pathway with the PI3K inhibitor LY294002 potentiated TP/HCPT-induced apoptosis in A549 cells, which is consistent with the notion that the Akt cascade provides survival signals that counter-balance the apoptotic response induced by TP/HCPT. Thus, despite differential involvement of MAPKs and Akt survival signaling cascades upon treatment with TP and HCPT, the activation of ERK1/2 and p38, and inhibition of Akt signal transduction pathway could plausibly all contribute to eliciting apoptosis in A549 cells. However, the potential of cross-talk between the MAPKs and Akt pathways still needs further investigation. 
Recently, protein phosphatase 2A (PP2A), an important protein serine/threonine phosphatase, is attracting more and more attention due to its apoptosis-inducing effect and tumor-suppressing function (36-38). In the present study, we observed that TP/HCPT stimulated a significant enhancement of PP2A activity, along with alterations of its composition subunits, including down-regulated PP2A catalytic C subunit, up-regulated PP2A structural A subunit, and decreased phosphorylation at PP2A-C Tyr307 (Y307). PP2A-A subunit, a scaffolding protein for the holoenzyme, is reported to allosterically modulate the enzymatic properties of PP2A-C (60), we thus reasoned that enhanced expression of PP2A-A might contribute to the induction of PP2A activity. Previous studies have revealed that post-translational modifications of the highly conserved carboxy-terminal sequence of PP2A-C subunit, especially the phosphorylation at Tyr307 can affect PP2A phosphatase activity $(35,39)$. In the present study, we found the depression of phosphorylation at PP2A-C Y307 closely matched the enhancement of PP2A activity.

PP2A is one of the most studied regulators of MAPKs and Akt by dephosphorylating the threonine or the tyrosine residue and thereby downregulate their activities $(32,40)$, and is known to directly interact with these kinases (41). Our previous study demonstrated that PP2A inhibition, by its specific inhibitor MC-LR, leads to a dramatic activation of p38-MAPK (28). In agreement with the prior findings, the present study demonstrated the downregulation of $\mathrm{p} 38$ and ERK MAPKs by PP2A, as a specific PP2A inhibitor of OA resulted in a significant increase in TP/HCPT-induced phosphorylation of ERK1/2 and p38. On the other hand, OA dramatically reversed the downregulation of Akt phosphorylation, suggesting the involvement of a phosphatase $2 \mathrm{~A}$ in TP/HCPT-induced dephosphorylation of Akt. However, our present study also showed that a significant increase in PP2A activity triggered by TP/HCPT was surprisingly accompanied by abnormal phosphorylation of ERK and p38, implying that the modulation of the MAPK signaling pathway is not all in a phosphatase-dependent manner. Actually, because the phosphorylation of MAPKs is a reversible process which is regulated by a coordinated balance between protein kinase-mediated phosphorylation and protein phosphatase-mediated dephosphorylation, it might be possible that, in addition to PP2A activation, TP/HCPT stimulate the activation of ERK- and p38-MAPK also by acting on the MAPKs upstream kinases, for example, MAPK kinases (MKKs) such as MKK1/2 (ERK upstream kinases) and MKK3/6 (p38 upstream kinases), and even the MKK upstream kinase MAPK kinase kinases (MKKKs) (61), which requires further research.

In conclusion, our study discovers a new mode of action of TP together with HCPT in anticancer therapy. To our knowledge, this is the first report demonstrating that TP and HCPT synergistically exert in vitro anticancer activity in human NSCLC A549 lung adenocarcinoma cells through induction of apoptosis. Importantly, our findings suggest that TP/HCPT trigger apoptosis in human lung cancer cells by activation of p38 and ERK MAPK cascades, and inhibition of the Akt survival pathway through a mechanism involving activation of PP2A, which uncover a molecular mechanism that may underlie this combinatorial therapy (Fig. 7). Additionally, such synergistic interactions, which allow for both TP and HCPT dose reduction, raise the interesting possibility that TP/HCPT may have a clinically beneficial effect on anticancer dose reduction and, thereby leading to a decrease in cytotoxicity during chemotherapy. Since our present conclusions were primarily based on in vitro studies, in vivo assessment of the anticancer effect of TP/HCPT in e.g., xenograft models is warranted. Further studies are required to improve our understanding of the synergistic anticancer action of TP/HCPT and to develop new combinatorial therapies for cancer.

\section{Acknowledgements}

This study was supported by Science Foundation from the Natural Science Foundation of Zhejiang Province (nos. LY12H29010 and LQ14H290002), Public Technology Applied Research Projects from Science and Technology Department of Zhejiang Province (no. 2013C33199) and Zhejiang Provincial Administration of Traditional Chinese Medicine (no. 2014ZB012).

\section{References}

1. He YY, Zhang XC, Yang JJ, et al: Prognostic significance of genotype and number of metastatic sites in advanced non-smallcell lung cancer. Clin Lung Cancer 15: 441-447, 2014.

2. Rajeswaran A, Trojan A, Burnand B and Giannelli M: Efficacy and side effects of cisplatin- and carboplatin-based doublet chemotherapeutic regimens versus non-platinum-based doublet chemotherapeutic regimens as first line treatment of metastatic non-small cell lung carcinoma: a systematic review of randomized controlled trials. Lung Cancer 59: 1-11, 2008.

3. Chen Y, Zhu J and Zhang W: Antitumor effect of traditional Chinese herbal medicines against lung cancer. Anticancer Drugs 25: 983-989, 2014

4. Wang S, Wu X, Tan M, et al: Fighting fire with fire: poisonous Chinese herbal medicine for cancer therapy. J Ethnopharmacol 140: 33-45, 2012.

5. Kupchan SM, Court WA, Dailey RG, Gilmore CJ and Bryan RF: Triptolide and tripdiolide, novel antileukemic diterpenoid triepoxides from Tripterygium wilfordii. J Am Chem Soc 94: 7194-7195, 1972.

6. Corson TW and Crews CM: Molecular understanding and modern application of traditional medicines: triumphs and trials. Cell 130: 769-774, 2007.

7. Liu Y, Xiao E, Yuan L and Li G: Triptolide synergistically enhances antitumor activity of oxaliplatin in colon carcinoma in vitro and in vivo. DNA Cell Biol 33: 418-425, 2014.

8. Zhao H, Yang Z, Wang X, et al: Triptolide inhibits ovarian cancer cell invasion by repression of matrix metalloproteinase 7 and 19 and upregulation of E-cadherin. Exp Mol Med 44: 633-641, 2012.

9. Nakazato T, Sagawa M and Kizaki M: Triptolide induces apoptotic cell death of multiple myeloma cells via transcriptional repression of Mcl-1. Int J Oncol 44: 1131-1138, 2014.

10. Chen F, Liu Y, Wang S, et al: Triptolide, a Chinese herbal extract, enhances drug sensitivity of resistant myeloid leukemia cell lines through downregulation of HIF-1 $\alpha$ and Nrf2. Pharmacogenomics 14: 1305-1317, 2013.

11. Wu PP, Liu KC, Huang WW, et al: Triptolide induces apoptosis in human adrenal cancer NCI-H295 cells through a mitochondrialdependent pathway. Oncol Rep 25: 551-557, 2011.

12. Mujumdar N, Banerjee S, Chen Z, et al: Triptolide activates unfolded protein response leading to chronic ER stress in pancreatic cancer cells. Am J Physiol Gastrointest Liver Physiol 306: G1011-G1020, 2014.

13. Li J, Liu R, Yang Y, Huang Y, Li X and Shen X: Triptolideinduced in vitro and in vivo cytotoxicity in human breast cancer stem cells and primary breast cancer cells. Oncol Rep 31: 2181-2186, 2014.

14. Hsiang YH, Hertzberg R, Hecht S and Liu LF: Camptothecin induces protein-linked DNA breaks via mammalian DNA topoisomerase I. J Biol Chem 260: 14873-14878, 1985. 
15. Zaki NM: Augmented cytotoxicity of hydroxycamptothecinloaded nanoparticles in lung and colon cancer cells by chemosensitizing pharmaceutical excipients. Drug Deliv 21: 265-275, 2014

16. Hu W, Zhang C, Fang Y and Lou C: Anticancer properties of 10-hydroxycamptothecin in a murine melanoma pulmonary metastasis model in vitro and in vivo. Toxicol In Vitro 25: 513-520, 2011.

17. Fu YR, Yi ZJ, Yan YR and Qiu ZY: Hydroxycamptothecininduced apoptosis in hepatoma SMMC-7721 cells and the role of mitochondrial pathway. Mitochondrion 6: 211-217, 2006.

18. Kotoh S, Naito S, Yokomizo A, et al: Increased expression of DNA topoisomerase I gene and collateral sensitivity to camptothecin in human cisplatin-resistant bladder cancer cells. Cancer Res 54: 3248-3252, 1994

19. Liu Y, Chen F, Wang S, et al: Low-dose triptolide in combination with idarubicin induces apoptosis in AML leukemic stem-like KG1a cell line by modulation of the intrinsic and extrinsic factors. Cell Death Dis 4: e948, 2013.

20. Alsaied OA, Sangwan V, Banerjee S, et al: Sorafenib and triptolide as combination therapy for hepatocellular carcinoma. Surgery 156: 270-279, 2014.

21. Tang XY,Zhu YQ, Tao WH, Wei B and Lin XL: Synergistic effect of triptolide combined with 5-fluorouracil on colon carcinoma. Postgrad Med J 83: 338-343, 2007.

22. Pigneux A, Mahon FX, Uhalde M, et al: Triptolide cooperates with chemotherapy to induce apoptosis in acute myeloid leukemia cells. Exp Hematol 36: 1648-1659, 2008.

23. Chen Z, Sangwan V, Banerjee S, et al: Triptolide sensitizes pancreatic cancer cells to TRAIL-induced activation of the death receptor pathway. Cancer Lett 348: 156-166, 2014.

24. Wang W, Yang S, Su Y, et al: Enhanced antitumor effect of combined triptolide and ionizing radiation. Clin Cancer Res 13: 4891-4899, 2007.

25. Yang SW, Wang W, Xie XY, Zhu WP and Li FQ: In vitro synergistic cytotoxic effect of triptolide combined with hydroxycamptothecin on pancreatic cancer cells. Am J Chin Med 39: 121-134, 2011.

26. Chou TC and Talalay P: Quantitative analysis of dose-effect relationships: the combined effects of multiple drugs or enzyme inhibitors. Adv Enzyme Regul 22: 27-55, 1984.

27. Chou TC: Theoretical basis, experimental design, and computerized simulation of synergism and antagonism in drug combination studies. Pharmacol Rev 58: 621-681, 2006.

28. Meng G, Sun Y, Fu W, Guo Z and Xu L: Microcystin-LR induces cytoskeleton system reorganization through hyperphosphorylation of tau and HSP27 via PP2A inhibition and subsequent activation of the p38 MAPK signaling pathway in neuroendocrine (PC12) cells. Toxicology 290: 218-229, 2011.

29. Zhao S, Xiong Z, Mao X, et al: Atmospheric pressure room temperature plasma jets facilitate oxidative and nitrative stress and lead to endoplasmic reticulum stress dependent apoptosis in HepG2 cells. PLoS One 8: e73665, 2013.

30. Han J, Back SH, Hur J, et al: ER-stress-induced transcriptional regulation increases protein synthesis leading to cell death. Nat Cell Biol 15: 481-490, 2013.

31. Nakagawa T, Zhu H, Morishima N, et al: Caspase-12 mediates endoplasmic-reticulum-specific apoptosis and cytotoxicity by amyloid-beta. Nature 403: 98-103, 2000.

32. Komatsu M, Furukawa T, Ikeda R, et al: Involvement of mitogen-activated protein kinase signaling pathways in microcystin-LR-induced apoptosis after its selective uptake mediated by OATP1B1 and OATP1B3. Toxicol Sci 97: 407-416, 2007.

33. Cowan KJ and Storey KB: Mitogen-activated protein kinases: new signaling pathways functioning in cellular responses to environmental stress. J Exp Biol 206: 1107-1115, 2003.

34. Downward J: Mechanisms and consequences of activation of protein kinase B/Akt. Curr Opin Cell Biol 10: 262-267, 1998

35. Sontag E: Protein phosphatase 2A: the Trojan Horse of cellular signaling. Cell Signal 13: 7-16, 2001.

36. Chen W, Wang Z, Jiang C and Ding Y: PP2A-mediated anticancer therapy. Gastroenterol Res Pract 2013: 675429, 2013.

37. Perrotti D and Neviani P: Protein phosphatase 2A: a target for anticancer therapy. Lancet Oncol 14: e229-e238, 2013.

38. Janssens V and Rebollo A: The role and therapeutic potential of Ser/Thr phosphatase PP2A in apoptotic signalling networks in human cancer cells. Curr Mol Med 12: 268-287, 2012.
39. Chen J, Martin BL and Brautigan DL: Regulation of protein serine-threonine phosphatase type-2A by tyrosine phosphorylation. Science 257: 1261-1264, 1992

40. Kuo YC, Huang KY, Yang CH, Yang YS, Lee WY and Chiang CW: Regulation of phosphorylation of Thr-308 of Akt, cell proliferation, and survival by the B55alpha regulatory subunit targeting of the protein phosphatase $2 \mathrm{~A}$ holoenzyme to Akt. J Biol Chem 283: 1882-1892, 2008.

41. Lee ER, Kim JH, Choi HY, Jeon K and Cho SG: Cytoprotective effect of eriodictyol in UV-irradiated keratinocytes via phosphatase-dependent modulation of both the p38 MAPK and Akt signaling pathways. Cell Physiol Biochem 27: 513-524, 2011.

42. Chen L, Liu L, Yin J, Luo Y and Huang S: Hydrogen peroxideinduced neuronal apoptosis is associated with inhibition of protein phosphatase $2 \mathrm{~A}$ and 5 , leading to activation of MAPK pathway. Int J Biochem Cell Biol 41: 1284-1295, 2009.

43. Li XJ, Jiang ZZ and Zhang LY: Triptolide: progress on research in pharmacodynamics and toxicology. J Ethnopharmacol 155: $67-79,2014$

44. Tan W, Lu J, Huang M, et al: Anti-cancer natural products isolated from chinese medicinal herbs. Chin Med 6: 27, 2011

45. Hengartner MO: The biochemistry of apoptosis. Nature 407: 770-776, 2000.

46. Chen YW, Huang CF, Yang CY, Yen CC, Tsai KS and Liu SH: Inorganic mercury causes pancreatic beta-cell death via the oxidative stress-induced apoptotic and necrotic pathways. Toxicol Appl Pharmacol 243: 323-331, 2010.

47. Carter BZ, Mak DH, Schober WD, et al: Triptolide induces caspase-dependent cell death mediated via the mitochondrial pathway in leukemic cells. Blood 108: 630-637, 2006.

48. Wang Q, Du H, Geng G, et al: Matrine inhibits proliferation and induces apoptosis via BID-mediated mitochondrial pathway in esophageal cancer cells. Mol Biol Rep 41: 3009-3020, 2014.

49. Li Y, Zhang S, Geng JX and Hu XY: Curcumin inhibits human non-small cell lung cancer A549 cell proliferation through regulation of Bcl-2/Bax and cytochrome C. Asian Pac J Cancer Prev 14: 4599-4602, 2013.

50. Qin R, Shen H, Cao Y, et al: Tetrandrine induces mitochondriamediated apoptosis in human gastric cancer BGC-823 cells. PLoS One 8: e76486, 2013.

51. Yip KW and Reed JC: Bcl-2 family proteins and cancer. Oncogene 27: 6398-6406, 2008.

52. Giorgi C, De Stefani D, Bononi A, Rizzuto R and Pinton P. Structural and functional link between the mitochondrial network and the endoplasmic reticulum. Int J Biochem Cell Biol 41: 1817-1827, 2009.

53. Deniaud A, Sharaf el dein O, Maillier E, et al: Endoplasmic reticulum stress induces calcium-dependent permeability transition, mitochondrial outer membrane permeabilization and apoptosis. Oncogene 27: 285-299, 2008

54. Pinton P, Giorgi C, Siviero R, Zecchini E and Rizzuto R: Calcium and apoptosis: ER-mitochondria $\mathrm{Ca}^{2+}$ transfer in the control of apoptosis. Oncogene 27: 6407-6418, 2008.

55. Shao H, Ma J, Guo T and Hu R: Triptolide induces apoptosis of breast cancer cells via a mechanism associated with the Wnt/ $\beta$ catenin signaling pathway. Exp Ther Med 8: 505-508, 2014.

56. Whitmarsh AJ and Davis RJ: Transcription factor AP-1 regulation by mitogen-activated protein kinase signal transduction pathways. J Mol Med (Berl) 74: 589-607, 1996.

57. Xia Z, Dickens M, Raingeaud J, Davis RJ and Greenberg ME: Opposing effects of ERK and JNK-p38 MAP kinases on apoptosis. Science 270: 1326-1331, 1995.

58. Lee ER, Kang YJ, Kim JH, Lee HT and Cho SG: Modulation of apoptosis in HaCaT keratinocytes via differential regulation of ERK signaling pathway by flavonoids. J Biol Chem 280: 31498-31507, 2005

59. Leung HW, Hour MJ, Chang WT, et al: P38-associated pathway involvement in apoptosis induced by photodynamic therapy with Lonicera japonica in human lung squamous carcinoma $\mathrm{CH} 27$ cells. Food Chem Toxicol 46: 3389-3400, 2008

60. Turowski P, Favre B, Campbell KS, Lamb NJ and Hemmings BA: Modulation of the enzymatic properties of protein phosphatase $2 \mathrm{~A}$ catalytic subunit by the recombinant $65-\mathrm{kDa}$ regulatory subunit PR65alpha. Eur J Biochem 248: 200-208, 1997.

61. Muslin AJ: MAPK signalling in cardiovascular health and disease: molecular mechanisms and therapeutic targets. Clin Sci (Lond) 115: 203-218, 2008. 